\title{
HPV infection-associated anogenital cyto-colpo-histological findings and molecular typing in HIV-positive women
}

\author{
F.K. Tso', C.L.L. Rodrigues ${ }^{2}$, J.E. Levi², M.G. Mattosinho de Castro Ferraz ${ }^{3}$, \\ N.M.G. Speck ${ }^{1}$ and J.C.L. Ribalta ${ }^{1}$ \\ ${ }^{1}$ Núcleo de Prevenção de Doenças Ginecológicas, Departamento de Ginecologia, \\ Escola Paulista de Medicina, Universidade Federal de São Paulo, \\ São Paulo, SP, Brasil \\ 'Laboratório de Virologia, Instituto de Medicina Tropical, Universidade de São Paulo, \\ São Paulo, SP, Brasil \\ ${ }^{3}$ Departamento de Patologia, Escola Paulista de Medicina, \\ Universidade Federal de São Paulo, São Paulo, SP, Brasil \\ Corresponding author: F.K. Tso \\ E-mail: fernandaktso@gmail.com
}

Genet. Mol. Res. 14 (4): 17630-17640 (2015)

Received June 12, 2015

Accepted September 2, 2015

Published December 21, 2015

DOI http://dx.doi.org/10.4238/2015.December.21.36

\begin{abstract}
HIV and human papillomavirus (HPV) coinfection is increasing, especially in the anal canal (AC) and cervico-vaginal regions. We identified anal epithelium abnormalities related to high-risk HPV (HR-HPV) lesions in the lower genital tracts (LGTs) of HIV-positive women, described the HPV genotypes identified, and assessed the expression of E6/E7 oncogenes in coinfected patients. Ninety-eight women were enrolled in groups combining HIV status and presence or absence of HPV in the LGT. Anal and cervical smears were collected for cytology and HR-HPV assays using Cobas ${ }^{\circledR}$ and/ or PapilloCheck ${ }^{\circledR}$. Samples with highly oncogenic HPV genotypes were confirmed by NucliSENS EasyQ ${ }^{\circledR}$. Forty-two HIV-positive (25-52; mean age $39.5)$ and 56 HIV-negative (18-58; mean age 35.7) patients were included. $E 2$ and $C 1$ groups presented $A C$ alterations $(P=0.002)$; altered images
\end{abstract}


for high-resolution anoscopy were higher in E1 and C2 $(P<0.001)$. Of the 29 women with alterations, $41.38 \%$ were HIV-negative and $58.62 \%$ were HIV-positive ( $P<0.001$ ). HIV-positive patients accounted for $29 \%$ of the anal high-grade squamous intraepithelial lesions $(P=0.015)$. The Cobas ${ }^{\circledR}$ positive result frequency was higher in three $\mathrm{AC}$ groups than in the other groups. There was variation in the number of HPV types in the cervicovaginal samples among the study groups $(P<0.001)$. Anal cytology and anoscopy showed more altered findings in HIV-positive patients with HPV in the LGT. HR-HPV anal infections by various genotypes are common and are associated with cervical infections in HIV-positive patients. E6/E7 expression is apparently more common in the AC of HIV-positive women.

Key words: HPV infection; HIV; Anal cancer; Anal cytology; E6/E7 mRNA

\section{INTRODUCTION}

Persistent high-risk human papillomavirus (HR-HPV) infection of the anal region leads to invasive squamous cell carcinoma of the anus (SCCA). Anogenital HPV infection is consistently multicentric and cervical HPV infections may be a source of viral dissemination in the anal epithelium (Hessol et al., 2013). In human immunodeficiency virus (HIV)-positive (HIV+) women, the prevalence of anal HPV infection is greater than that of cervical infection. The incidence of SCCA is particularly high in HIV+ men and women (Poggio, 2011). HIV+ women more frequently present persistent infection with multiple HPV genotypes (Corrêa et al., 2011; Pantanowitz and Michelow, 2011), probably owing to the inability of an HIV-compromised system to control the expression and replication of HPV (Tornesello et al., 2008).

Anal high-grade squamous intraepithelial lesions (HSILs) are considered a premalignant precursor of anal cancer (Darragh and Winkler, 2011), and there has been a continuous increase in their incidence in people who have been living with HIV and are receiving highly active antiretroviral therapy (HAART) (Palefsky, 2009).

Cytology of the anal canal $(A C)$ is increasingly used for diagnosis in high-risk populations; the screening scheme is similar to that used for cervical cancer. Initially, patients undergo screening using the Pap smear test; abnormal anal cytology, e.g., the presence of squamous intraepithelial lesions (SILs), is detected by high-resolution anoscopy (HRA), which permits biopsies and the identification of abnormal tissue (Dandapani et al., 2010; Gimenez et al., 2011), In some groups, particularly in younger age groups, almost all infections are transient and asymptomatic; the majority of infections spontaneously disappear. Thus, specific methods of HPV detection for severe dysplasia are required especially in risk groups (Molden et al., 2006). There is clinical evidence that molecular tests for oncogenic HPV types and their activity provide higher sensitivity for the detection of cervical HSILs (Naucler et al., 2009), but none has been approved for use as a screening test in the AC (Darragh and Winkler, 2011). However, the risk of progression from anal intraepithelial neoplasia to anal cancer has steadily increased to almost $50 \%$ in HIV+ patients (Dandapani et al., 2010). The oncogenic potential of HPV lies in the E6 and E7 proteins (E6/E7), which bind and modulate different types of genetic products. These interactions lead to genomic instability, and the expression of E6/E7 is vital for malignancy transformation (Kraus et al., 2006). Tests that monitor E6/E7 activity by messenger RNA (mRNA) detection seem to be a good strategy for stratifying individuals with HR-HPV and evaluating their chances of developing cancer in the lower genital tract (LGT) (Szarewski et al., 
2008). Few authors have studied the applicability of this test for AC screening, and most of the tests have been conducted on men who have intercourse with men (Silling et al., 2012; Wentzensen et al., 2012). This study might contribute to better prognoses and widen knowledge about HR-HPV and HIV coinfection in women. The objective of the present study was to evaluate and relate to the presence of abnormalities caused by HPV infection in the anal epithelium of HIV-seropositive women using HRA. We also aimed to describe HPV genotypes in the LGT and AC, and investigate E6/E7 oncogene expression by mRNA detection in HSILs.

\section{MATERIAL AND METHODS}

\section{Study population}

The transversal case-control observational study was conducted at the Department of Lower Genital Tract Pathology-Gynecology Department of the Federal University of São Paulo, from April 2010 to April 2012. The Ethics and Research Committee of the Federal University of São Paulo (UNIFESP/EPM) under protocol number 0508/06 approved the study. Written informed consent was obtained from all participants prior to enrollment.

A total of 98 18- to 58-year-old women were selected. The HIV+ cases, called the study group, had been referred to the infectology sector of the University, where they were clinically followed up for gynecological assessment. The control group had been referred to the sector owing to cytological alterations or benign LGT diseases, and were subjected to the HIV test to confirm absence of infection.

Women who were experiencing puerperal infections, were in a non-HIV immunosuppressing condition, or who had been submitted for clinical or surgical procedures involving the anus and/or AC 3 months prior to selection were excluded. Four groups were classified: Study 1 (E1), patients with HIV+ and HPV-induced LGT lesions; Study 2 (E2), patients with HIV+ and no HPVinduced LGT lesions; Control 1 (C1), HIV-negative (HIV-) patients with HPV-induced LGT lesions; and Control 2 (C2), HIV- patients without HPV-induced LGT lesions.

\section{Cytology, colposcopy, anoscopy, and histology}

Briefly, the women were submitted to general physical examinations and the anal and cervico-vaginal (CV) cytopathologic swab specimens were collected for cytology and HPV genotyping; the procedures have been described previously by Wentzensen et al. (2012) and were adapted in our laboratory.

The cytological examinations were performed according to the standard technique. Collected cells were initially prepared for conventional cytology by directly spreading cells onto a glass slide and immediately immersing the slide in absolute ethanol for fixation. Both anal and cervical cytology was classified according to the Bethesda system (2001) because the anus and cervix have similar histopathologic features (Poggio, 2011; Cambou et al., 2015)

The cells remaining in the swab were then collected and immersed in a flask containing $20 \mathrm{~mL}$ ThinPrep ${ }^{\circledR}$ (Hologic, Bedford, MA, USA) refrigerated solution. The samples were processed and analyzed at the Institute of Tropical Medicine of the University of São Paulo. The same physician carried out the colposcopies and HRAs on all the women. The cervical colposcopic results were classified under the International Terminology for Colposcopic Findings determined in Rio de Janeiro in 2011, as were the findings for AC (Quaas et al., 2013, 2014). Abnormal findings identi- 
fied by colposcopy or HRA were biopsied and sent for histopathological review. The results were reported as negative and intraepithelial neoplasia grades 1 to 3 .

\section{HPV DNA detection assay}

Initially, we used the Cobas $^{\circledR} 4800$ (Roche, Branchburg, NJ, USA) system to screen for HR-HPV DNA. The system allows fully automated sample preparation and includes real-time polymerase chain reaction (PCR) ABI Prism ${ }^{\circledR} 7300$ HT SDS (Applied Biosystems Inc., Leipzig, Germany) equipment.The assay process extracts, amplifies, and detects a total of $14 \mathrm{HR}-\mathrm{HPV}$ genotypes: 12 over a broad spectrum $(31,33,35,39,45,51,52,56,58,59,66$, and 68); and, separately two additional HPV genotypes (16 and 18). It simultaneously identifies the endogenous gene for $\beta$-globin, which indicates human cellularity in the specimen. The system operates over four separate reporter days and tracks the different targets in the multiplex reaction; it amplifies a region of approximately $200 \mathrm{bp}$ within the L1 polymorphic region of the HPV genome. The Cobas ${ }^{\circledR}$ 4800 assay was carried out following the manufacturer instructions, as previously described (Gage et al., 2012; Agorastos et al., 2015).

The samples that amplified the HR-HPV DNA in the Cobas ${ }^{\circledR} 4800$ method were subjected to a PapilloCheck ${ }^{\circledR}$ (Greiner Bio-One $\mathrm{GmbH}$, Frickenhausen, Germany) assay, which is a PCR-based DNA microarray system that uses a consensus primer set that targets the E1 region of HPV DNA and amplifies a fragment of $350 \mathrm{bp}$. The assay simultaneously detects and identifies 24 HPV genotypes, including 15 HR-HPV genotypes (16, 18, 31, 33, 35, 39, 45, 51, 52, 56, 58, 59, 68, 73, and 82), two probable HR-HPV genotypes (53 and 66), and seven low-risk HPV (LR-HPV) genotypes (6, 11, 40, $42,43,44$, and 70). The method was performed according to the manufacturer instructions.

For the samples with negative Cobas $^{\circledR} 4800$ assay results, but with cytological and/or anatomopathological examination results suggesting viral alteration, the genotyping was carried out using the PapilloCheck ${ }^{\circledR}$ method to identify other HPV types not defined in the first test (HPV 6, $11,40,43,44,55,65,70,73$, and 82).

\section{Detection of E6/E7 mRNA}

The samples that presented positive results for one or more highly oncogenic HPV type $(16,18,31,33$, or 45$)$ were subjected to the NucliSENS EasyQ ${ }^{\circledR}$ HPV (bioMerieux, Marcy l'Etoile, France) test to investigate the expression of E6/E7 oncogenes. ThinPrep ${ }^{\circledR}$ specimens $(5 \mathrm{~mL})$ were then subjected to DNA and RNA extraction using the automated NucliSENS ${ }^{\circledR}$ easyMAG $^{\circledR}$ (bioMerieux) system, as described previously (Capaul and Gorgievski-Hrisoho, 2005). The mRNA assay was carried out to detect HPV E6/E7 from the mRNA of the 16, 18, 31, 33, and 45 genotypes by real-time multiplex nucleic acid sequence-based amplification using the NucliSENS Easy ${ }^{\circledR} \mathrm{HPV}$, according to the manufacturer protocols.

\section{Statistical analysis}

Analyses were performed using the SPSS statistical package (18.0 version; Chicago, IL, USA). For a comparison of quantitative variables among the groups, analysis of variance or Kruskal-Wallis tests were used, and the qualitative tests were performed by chi-square tests and/ or the exact Fisher test. McNemar or McNemar-Bowker tests were used to compare CV and anal variables. Statistical significance was established as $5 \%$ or $\mathrm{P}<0.05$. 


\section{RESULTS}

The study comprised 56 women in the control group (aged 18-58 years; mean age 35.7) and 42 women in the study group (aged 25-52 years; mean age 39.5). The sample profile was considered homogeneous in the following criteria: ethnic group $(P=0.898)$, smoking habits $(P=$ $0.976)$, coitarche $(P=0.259)$, number of sexual partners $(P=0.582)$, number of pregnancies $(P=$ $0.473)$, anal intercourse $(P=0.590)$, and CD4 level among HIV carriers $(P=0.129)$.

The study group E2 and control group $\mathrm{C} 1$ presented a high frequency of cytological alterations in the $A C(P=0.002)$, but altered images for HRA were higher in $E 1$ and $C 2(P<0.001)$, and the differences were statistically significant.

The HIV+ patients in the study group with altered cervical cytology also presented anal epithelium alterations in $52.7 \%$ of cases, while the negative CV cytology was $39.2 \%$ and presented cytological alteration for the AC; there was no significant statistical association, as shown in Table $1(P=1.000)$.

Table 1. Patient distribution in the study group $(\mathrm{N}=42)$ according to cervico-vaginal $(\mathrm{CV})$ and anal canal $(\mathrm{AC})$ cytopathology.

\begin{tabular}{|c|c|c|c|c|c|c|}
\hline \multirow[t]{3}{*}{ CV cytopathological test } & \multicolumn{6}{|c|}{ AC cytopathological test } \\
\hline & \multicolumn{2}{|c|}{ Altered } & \multicolumn{2}{|c|}{ Not altered } & \multicolumn{2}{|c|}{ Total } \\
\hline & $\mathrm{N}$ & $\%$ & $\mathrm{~N}$ & $\%$ & $\mathrm{~N}$ & $\%$ \\
\hline Altered & 10 & 52.7 & 9 & 47.3 & 19 & 100 \\
\hline Not altered & 9 & 39.2 & 14 & 60.8 & 23 & 100 \\
\hline Total & 19 & 45.2 & 23 & 54.8 & 42 & 100 \\
\hline
\end{tabular}

McNemar test: $P=1.000$.

The 98 women were evaluated by anoscopy in the AC and anus: $25.51 \%$ had altered images revealed by HRA [low-grade squamous intraepithelial lesions (LSILs) or HSILs)], and underwent biopsy; $4.08 \%$ did not have any neoplasia; and $70.41 \%$ did have altered images and therefore underwent biopsy. For $29.59 \%$ (29/98) of the women mentioned before that had notable alterations, $41.38 \%$ (12/29) were HIV- (control group) and 58.62\% (17/29) were HIV+ (study group); the difference was statistically significant $(P<0.001)$.

The anatomopathological reports revealed alterations in 25 biopsy samples. LSILs were present in $83 \%$ of the AC biopsies in patients in the control group and present in $59 \%$ of the study group patients. Anal HSILs were present in $29 \%$ of the HIV+ women and absent in the HIV- women.

An analysis of women submitted for AC biopsy revealed statistically significant difference between the control and study groups $(P=0.015)$.

The positive result frequency in the Cobas $^{\circledR} 4800$ test was higher in three AC groups (E1 $A C, E 2 A C$, and $C 1 A C$ ) than in all the other groups (Figure 1). Statistically significant differences were found in the variation of the number of HPV types present in the CV samples among the study groups $(P<0.001)$. A higher number of different HPV types were noticed in each sample, and the multiple infections with two or more HPV genotype were notable in patients bearing HPV-induced lesions in the LGT, especially in the HIV+ cases.

Regarding the number of HPV types identified in the AC samples, we observed statistically significant differences among the study groups $(P=0.003)$. HIV+ groups occurred in more infections by different HPV genotypes (Figure 1). 


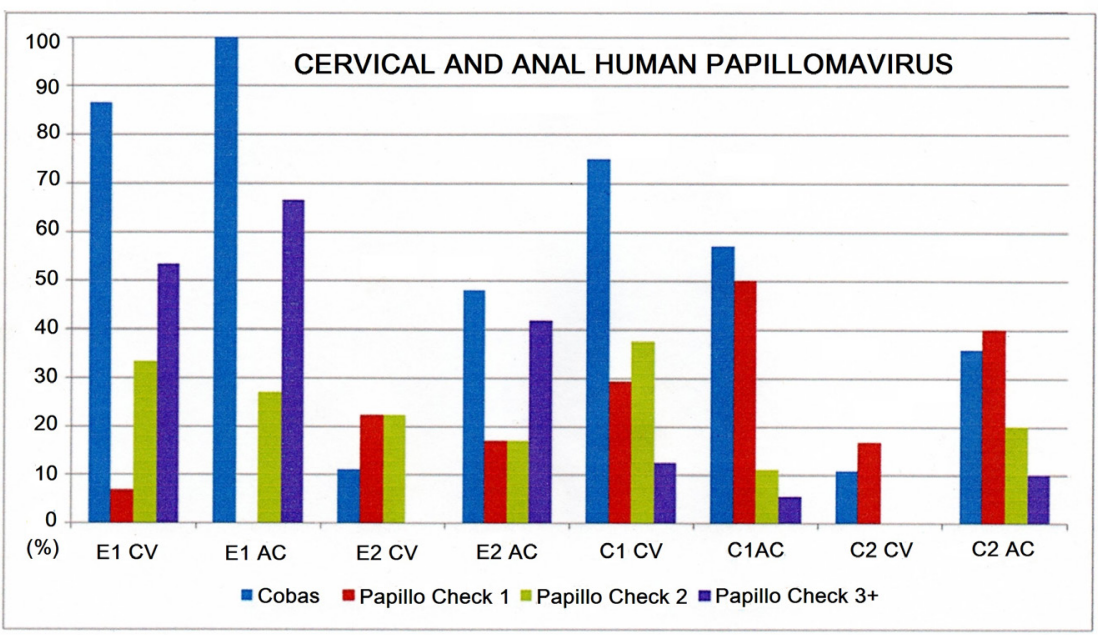

Figure 1. High-risk human papillomavirus (HR-HPV) prevalence in positive cervical and anal sample screening by Cobas $^{\circledast} 4800$ and HPV genotype variation using the PapilloCheck ${ }^{\circledast}$ test in cervico-vaginal (CV) and anal canal (AC) samples from the E1 and E2 Study groups (statistical analysis of CV and AC samples in the study groups by Cobas ${ }^{\circledR}$ 4800: $\chi^{2}=46.946$, d.f. $=3, \mathrm{P}<0.001$, Fisher $\mathrm{P}<0.001 ; \chi^{2}=17.051$, d.f. $=3, \mathrm{P}<0.001$, Fisher $\mathrm{P}<0.001$, respectively). Statistical analysis of the distribution of HPV genotype by PapilloCheck ${ }^{\circledR}$ test in $\mathrm{CV}$ and AC between control and study groups: $\chi^{2}=27.830, \mathrm{df}=9, \mathrm{P}=0.001$, Fisher $\mathrm{P}=0.001 ; \chi^{2}=23.818, \mathrm{df}=9, \mathrm{P}=0.005$, Fisher $\mathrm{P}<0.001$, respectively).

Of the $42 \mathrm{CV}$ samples from HIV+ patients, $38.1 \%$ (16) presented a positive Cobas ${ }^{\circledR} 4800$ result and $61.9 \%(26)$ were negative. Of the positive samples, only $25 \%(4 / 16)$ exhibited the highly oncogenic HPV genotypes $(16,18,31,33$, and 45$)$. All patients had mRNA expression in accordance with the Cobas ${ }^{\circledR} 4800$ assay for HPV genotypes (Table 2).

Table 2. Distribution of the 98 women in the control $(N=56)$ and study $(N=42)$ groups in terms of the Cobas ${ }^{\circledR}$ 4800 assay results from cervico-vaginal (CV) and anal canal (AC) samples.

\begin{tabular}{|c|c|c|c|c|c|c|c|c|}
\hline \multirow[t]{3}{*}{$\overline{\text { Cobas }^{\oplus}}$} & \multicolumn{4}{|c|}{ Study (HIV+) } & \multicolumn{4}{|c|}{ Control (HIV-) } \\
\hline & \multicolumn{2}{|c|}{ CV samples } & \multicolumn{2}{|c|}{ AC samples } & \multicolumn{2}{|c|}{ CV samples } & \multicolumn{2}{|c|}{ AC samples } \\
\hline & $\mathrm{N}$ & $\%$ & $\mathrm{~N}$ & $\%$ & $\mathrm{~N}$ & $\%$ & $\mathrm{~N}$ & $\%$ \\
\hline Positive & 16 & 38.1 & 28 & 66.7 & 24 & 42.9 & 26 & 46.4 \\
\hline Negative & 26 & 61.9 & 14 & 33.3 & 32 & 57.1 & 30 & 53.6 \\
\hline Total & 42 & 100.0 & 42 & 100.0 & 56 & 100.0 & 56 & 100.0 \\
\hline
\end{tabular}

In parallel to the $42 \mathrm{CV}$ samples from the HIV+ patients, the AC samples were analyzed by Cobas $^{\circledR} 4800$ and/or PapilloCheck ${ }^{\circledR} ; 66.7 \%$ (28) were positive and $33.3 \%$ (14) were negative. Of the positive samples, only $57.14 \%$ (16/28) showed highly oncogenic HPV genotypes in the tests. E6/E7 mRNA was observed only in cases with highly oncogenic HPV, i.e., $87.5 \%$ (14/16) of the samples had expression, and three registered multiple infection by highly oncogenic genotypes, HPV 16/45, HPV 18/33, and HPV 18/45.

Differences between the frequencies of positive Cobas ${ }^{\circledR} 4800$ results in the Study and control groups for $\mathrm{CV}$ and $\mathrm{AC}$ samples were statistically significant $(\mathrm{P}<0.001$; Table 3$)$. 
Table 3. Seropositive and seronegative HIV women $(\mathrm{N}=98)$ in the control and study subgroups and the distribution of positive and negative Cobas $^{\circledR} 4800$ assay results in the cervico-vaginal (CV) and anal canal (AC) regions.

\begin{tabular}{|c|c|c|c|c|c|c|c|c|c|c|}
\hline \multirow[t]{4}{*}{ Group } & & \multicolumn{9}{|c|}{ Cobas $^{\circledast} 4800$ test } \\
\hline & \multicolumn{4}{|c|}{ CV samples } & \multicolumn{6}{|c|}{ AC samples } \\
\hline & \multicolumn{2}{|c|}{ Positive } & \multicolumn{2}{|c|}{ Negative } & \multicolumn{2}{|c|}{ Positive } & \multicolumn{2}{|c|}{ Negative } & \multicolumn{2}{|c|}{ Total } \\
\hline & $\mathrm{N}$ & $\%$ & $\mathrm{~N}$ & $\%$ & $\mathrm{~N}$ & $\%$ & $\mathrm{~N}$ & $\%$ & $\mathrm{~N}$ & $\%$ \\
\hline E1 & 13 & 86.7 & 2 & 13.3 & 15 & 100.0 & - & - & 15 & 100.0 \\
\hline E2 & 3 & 11.1 & 24 & 88.9 & 13 & 48.1 & 14 & 51.9 & 27 & 100.0 \\
\hline C1 & 21 & 75.0 & 7 & 25.0 & 16 & 57.1 & 12 & 42.9 & 28 & 100.0 \\
\hline $\mathrm{C} 2$ & 3 & 10.7 & 25 & 89.3 & 10 & 35.7 & 18 & 64.3 & 28 & 100.0 \\
\hline Total & 40 & 40.8 & 58 & 59.2 & 54 & 55.1 & 44 & 44.9 & 98 & 100.0 \\
\hline
\end{tabular}

\section{DISCUSSION}

Despite the important and well-established causal relationship between persistent HRHPV infection and the development of AC cancer, no agreement on an optimum screening schedule has yet been reached (Pimenta et al., 2011). The molecular features of anal disease are similar to those of cervical lesions (Wentzensen et al., 2012). Since 2013, the Brazilian Ministry of Health has recommended the annual collection of material from HIV+ people for oncotic cytology (Greco et al., 2013).

In some studies, the sensitivity of oncotic cytology in AC samples varies from 50 to $80 \%$. In patients with a high frequency of HPV-induced lesions in the AC, as in men who have intercourse with men, the sensitivity is higher in the HIV+ individuals (Stier et al., 2015).

The results of oncotic cytology in the AC of the patients showed a higher frequency of alteration. This alteration was present in women with HPV-induced lesions in the LGT, especially among HIV+ patients. This result was expected and was in accordance with the results reported by other authors who have established a positive relationship between cytological alterations of the LGT and the AC in the HIV+ population (Kojic et al., 2011). In our study, HIV+ patients presented an altered $\mathrm{AC}$ in $42.9 \%$ of cases, and the figure was $26.8 \%$ in HIV- women. Our result for the $\mathrm{HIV}+$ patients differed from that reported from another Brazilian study performed by Cambou et al. (2015), where $30.4 \%$ of HIV+ women presented alterations in AC cytology. The difference between the results is likely to be due to the restricted number of samples in our study.

Cytologies classified as ASC-US were more prevalent among HIV+ patients, representing $9.5 \%$ in both CV and anal samples. HIV-seronegative patients exhibited percentages below $5 \%$ of ASC-US in CV samples and $7.1 \%$ in anal samples. This outcome may reflect the difficulties faced by cytopathologists in classifying AC samples. The graduation of cytological alterations in AC does not have clinical importance, and HRA is advisable in the presence of any cytological alteration. Anal cytology performed during HRA has frequently led to an underestimation of the seriousness of histological lesions (Palefsky et al., 2005).

There was an abnormally high frequency of altered images in the AC epithelium in the E1 group, wich reached $73.3 \%$ of cases. In contrast, the E2 group presented HRA results that showed the percentage with altered images was very like that in the HIV- patients, with HPVinduced lesions in the LGT.

In several studies, HRA revealed a sensitivity varying from 56 to $100 \%$ and a specificity from 66 to $74 \%$; as with cytology, there is performance improvement in populations with a higher 
prevalence of HIV (Gimenez et al., 2011). The usefulness of HRA as a diagnostic method depends on the ability of the healthcare professionals who utilize it, and the current obstacle for its implementation as a routine technique is the lack of technical expertise (Darragh and Winkler, 2011).

The anatomopathological results of the AC biopsies showed $100 \%$ histological alteration in the groups with HPV-induced lesions in the LGT, both in HIV+ and HIV- women. Among the groups without HPV-induced lesions in the LGT, only $50 \%$ of the AC biopsies presented histological alteration in HIV- and $66.7 \%$ in HIV+ patients.

Interestingly, $29.4 \%$ of the biopsies from HIV+ patients revealed anal HSILs, while there were no histological results for anal HSILs in the HIV- patients. Stanley et al. (2012) affirmed that immunocompromised patients presented SILs with higher risk of progression and evolution to cancer in comparison with immunocompetent patients.

The frequencies of positive Cobas ${ }^{\circledR} 4800$ test results from the $\mathrm{CV}$ and $\mathrm{AC}$ samples for the HIV+ patients were of 38.1 and $66.7 \%$, respectively, and for the HIV-patients they were 42.9 and $46.4 \%$, respectively. This outcome is similar to the results reported in the literature that highlight the prevalence of HPV DNA in the AC (Hessol et al., 2009).

All HIV+ patients that presented positive results from the Cobas ${ }^{\circledR} 4800$ test in CV smears showed positive results to the same test in AC smears. The rate of HIV- women indicating positive results from the Cobas ${ }^{\circledR} 4800$ test was $62.5 \%$ in both CV and AC smears. A cohort study conducted in Hawaii by Goodman et al. (2010) demonstrated that HPV anal infection was likely to be acquired after initial cervical infection. Curiously, our data revealed that nearly half of HIV+ and one-third of HIV- samples indicated the presence of HPV DNA in the anus, but the results for the cervical smears were negative according to Cobas $^{\circledR} 4800$.

The C2 group presented positive Cobas ${ }^{\circledR} 4800$ test results in only $10.7 \%$ of cervical samples, but $35.7 \%$ in AC samples. Despite the high frequency of positive results for HPV DNA in the $A C$, the HRA revealed altered images in $14.3 \%$ of the samples, and only half of the biopsies histologically confirmed HPV-related lesions, with no occurrence of anal HSILs. This result is similar to the standard result for the LGTs of a young population in relation to HPV DNA-positive results and the presence of histological lesions. The high incidence of positve results for HPV DNA in the AC of HIV-seronegative women without HPV-induced lesions in the LGT suggests a limited clinical usefulness as a primary screening method. To date, the American Food and Drug Administration has not approved any molecular test for screening HPV in AC cancer (Darragh and Winkler, 2011).

$\mathrm{HIV}+$ patients presented a higher frequency of multiple infection by HPV genotypes that are less prevalent in the population as a whole, and this LR-HPV can very often lead to HSILs. Some authors, such as Corrêa et al. (2011) and Pantanowitz and Michelow (2011), have demonstrated that the most frequent HPV genotypes in studies among the general population differ from those found in HIV- women.

Our data showed that in the HIV+ women the HPV genotypes considered highly oncogenic $(16,18,31,33$, and 45$)$ had a prevalence of $25 \%$ in the CV smears and $57.14 \%$ in the AC smears. In an analytic and clinical study, Wentzensen et al. (2014) emphasized that a combination of anal cytology and HPV genotyping provided the highest accuracy for detecting anal precancer, and Cobas $^{\circledR} 4800$ can be used for HPV detection in anal cytology specimens. In the same way, Cui et al. (2014) and Agorastos et al. (2015) demonstrated that HPV testing usually has a higher degree of sensitivity and specificity in detecting HR-HPV compared with cytology.

In view of the cervical samples submitted to the PapilloCheck ${ }^{\circledR}$ assay, over half of the E1 group demonstrated three or more HPV genotypes, and in $6.7 \%$ of the cases just one HPV genotype was observed.

The AC presented the highest multiplicity of HPV genotypes in HIV+ patients; however, 
$66.75 \%$ of women with HPV-induced LGT lesions had three or more genotypes, and $41.7 \%$ of women had no LGT lesions.

We noticed from the cytology data, the HPV DNA assays, and the HRA results that alterations were most prevalent in the HPV-induced LGT lesion groups, independently of HIV status.

Assessing the multiplicity of HPV genotypes present in the AC, the HIV status was more relevant than the presence of HPV-induced lesions in the LGT. As previously described, women with HPV-induced lesions in the LGT are at higher risk of anal SILs (Cambou et al., 2015). For not dealing with a prospective study, it was not conclusive therefore the definition of the cytology role, of HRA and the HPV DNA test on the prevention of AC cancer and the decrease of mortality by this disease. The patient attendance could show us how they evolved and the behavior of the disease.

Notably, tests based on E6/E7 gene expression by means of detecting the mRNA of some HPV types have demonstrated better specificity and higher positive predictive value than Hybrid Capture and PCR in screening for HSILs in the LGT (Szarewski et al., 2008).

Based on these findings and with an objective of assessing the mRNA expression in HIV+ patients, the samples that showed positive results for highly oncogenic HPV genotypes by Cobas $^{\circledR}$ 4800 and/or PapilloCheck ${ }^{\circledR}$ tests were subjected to the NucliSENS EasyQ ${ }^{\circledR}$ HPV assay.

A higher expression of mRNA E6/E7 was apparent in the AC smears of the HIV+ patients, with more than one-third presenting a positive result.

Four CV samples presented one or more highly oncogenic HPV genotype; all of them were positive for mRNA E6/E7 expression, which corresponded to $9.5 \%$ of cases, and the biopsies revealed LSILs.

In the HIV+ group comprising 42 samples from the AC, 57.14\% (16/28) showed one or more highly oncogenic HPV and $87.5 \%$ (14/16) were positive for mRNA E6/E7 expression, i.e., $33.33 \%$ of the total cases. Three of them (the 16 cases mentioned above) exhibited HSILs in the biopsy, five had LSILs, five had unaltered HRA images so biopsy was not necessary, and there were two negative smears for mRNA E6/E7 presenting LSILs in the biopsy.

Valari et al. (2011) studied 235 HIV- women forwarded for colposcopy owing to cytological alterations, and found HR-HPV in the AC in $31 \%$ of patients, but only $8 \%$ of those exhibited mRNA E6/E7 expression. In our study, the respective findings were 38.9\% (16/42) and 33.33\% (14/42), demonstrating the importance of HPV infection as a risk factor for positive E6/E7 mRNA expression. Molden et al. (2007) reported that the individual identification of E6/E7 mRNA expression may be an important reproducible assay that could help monitor HPV infections that produce proteins with transforming potential. However, Andersson et al. (2006) affirmed that E6/E7 oncogene expression analysis is consistent, but may serve to complement the results from other molecular tests.

It is necessary to emphasize that more revisions are essential to improve the screening methods for LGT lesions. Owing to the restricted number of samples and several anatomopathological findings in view of the positive cases of mRNA E6/E7 expression in our study, it was not possible to assess the usefulness of NucliSENS EasyQ ${ }^{\circledR} \mathrm{HPV}$ for the screening and diagnosis of HPV-induced lesions in the AC of seronegative and seropositive HIV patients. Prospective studies with larger sample sizes are necessary to determine the importance and the profile of each diagnostic method in the screening and prevention of AC cancer. It is important to take into account that evidence of anal HPV infection and dysplasia is common in women, especially in those who are HIV+ or have a history of infection with HPV in the LGT. The incidence of AC cancer continues to grow, mainly in HIV+ women, despite the widespread use of combined antiretroviral therapy (Stier et al., 2015).

In conclusion, anal cytology and HRA showed altered findings more often in HIV+ women. HPV infection of the anus with high-risk genotypes appears to be common and is associated with 
cervical infection, particularly in HIV+ patients. Anal HPV E6/E7 mRNA expression was apparently more frequent than cervical HPV E6/E7 mRNA expression in HIV+ women.

\title{
Conflicts of interest
}

The authors declare no conflict of interest.

\section{ACKNOWLEDGMENTS}

\author{
Research supported by a CAPES grant.
}

\section{REFERENCES}

Agorastos T, Chatzistamatiou K, Katsamagkas T, Koliopoulos G, et al. (2015). Primary screening for cervical cancer based on high-risk human papillomavirus (HPV) detection and HPV 16 and HPV 18 genotyping, in comparison to cytology. PLoS One 10: e0119755.

Andersson S, Hansson B, Norman I, Gaberi V, et al. (2006). Expression of E6/E7 mRNA from 'high risk' human papillomavirus in relation to CIN grade, viral load and p16INK4a. Int. J. Oncol. 29: 705-711.

Cambou MC, Luz PM, Lake JE, Levi JE, et al. (2015). Anal human papillomavirus (HPV) prevalences and factors associated with abnormal anal cytology in HIV-infected women in an urban cohort from Rio de Janeiro, Brazil. AIDS Patient Care STDS 29: 4-12.

Capaul SE and Gorgievski-Hrisoho M (2005). Detection of enterovirus RNA in cerebrospinal fluid (CSF) using NucliSens EasyQ Enterovirus assay. J. Clin. Virol. 32: 236-240.

Corrêa CM, Teixeira NC, Araújo AC, Carvalho Nde O, et al. (2011). Prevalence and multiplicity of HPV in HIV women in Minas Gerais, Brazil. Rev. Assoc. Med. Bras. 57: 425-430.

Cui M, Chan N, Liu M, Thai K, et al. (2014). Clinical performance of Roche Cobas 4800 HPV Test. J. Clin. Microbiol. 52: $2210-2211$.

Dandapani SV, Eaton M, Thomas CR Jr and Pagnini PG (2010). HIV-positive anal cancer: an update for the clinician. J. Gastrointest. Oncol. 1: 34-44.

Darragh TM and Winkler B (2011). Anal cancer and cervical cancer screening: key differences. Cancer Cytopathol. 119: 5-19.

Gage JC, Sadorra M, Lamere BJ, Kail R, et al. (2012). Comparison of the cobas Human Papillomavirus (HPV) test with the hybrid capture 2 and linear array HPV DNA tests. J. Clin. Microbiol. 50: 61-65.

Gimenez F, Costa-e-Silva IT, Daumas A, Araújo Jd, et al. (2011). The value of high-resolution anoscopy in the diagnosis of anal cancer precursor lesions in HIV-positive patients. Arq. Gastroenterol. 48: 136-145.

Goodman MT, Shvetsov YB, McDuffie K, Wilkens LR, et al. (2010). Sequential acquisition of human papillomavirus (HPV) infection of the anus and cervix: the Hawaii HPV Cohort Study. J. Infect. Dis. 201: 1331-1339.

Greco DB, Barbosa E, Filho Burgos R, de Freitas MA, et al. (2013). Protocolo clínico e diretrizes terapêuticas para adultos vivendo com HIVIAIDS. Ministério da Saúde - Secretaria de Vigilância em Saúde. Brazil, 1-75.

Hessol NA, Holly EA, Efird JT, Minkoff H, et al. (2009). Anal intraepithelial neoplasia in a multisite study of HIV-infected and high-risk HIV-uninfected women. AIDS 23: 59-70.

Hessol NA, Holly EA, Efird JT, Minkoff H, et al. (2013). Concomitant anal and cervical human papillomavirusV infections and intraepithelial neoplasia in HIV-infected and uninfected women. AIDS 27: 1743-1751.

Kojic EM, Cu-Uvin S, Conley L, Bush T, et al. (2011). Human papillomavirus infection and cytologic abnormalities of the anus and cervix among HIV-infected women in the study to understand the natural history of HIVIAIDS in the era of effective therapy (the SUN study). Sex Transm. Dis. 38: 253-259.

Kraus I, Molden T, Holm R, Lie AK, et al. (2006). Presence of E6 and E7 mRNA from human papillomavirus types 16, 18, 31, 33, and 45 in the majority of cervical carcinomas. J. Clin. Microbiol. 44: 1310-1317.

Molden T, Kraus I, Karlsen F, Skomedal H, et al. (2006). Human papillomavirus E6/E7 mRNA expression in women younger than 30 years of age. Gynecol. Oncol. 100: 95-100.

Molden T, Kraus I, Skomedal H, Nordstrøm T, et al. (2007). PreTect HPV-Proofer: real-time detection and typing of E6/E7 mRNA from carcinogenic human papillomaviruses. J. Virol. Methods 142: 204-212.

Naucler P, Ryd W, Törnberg S, Strand A, et al. (2009). Efficacy of HPV DNA testing with cytology triage and/or repeat HPV DNA testing in primary cervical cancer screening. J. Natl. Cancer Inst. 101: 88-99. 
Palefsky J (2009). Human papillomavirus-related disease in people with HIV. Curr. Opin. HIV AIDS 4: 52-56.

Palefsky JM, Holly EA, Efirdc JT, Da Costa M, et al. (2005). Anal intraepithelial neoplasia in the highly active antiretroviral therapy era among HIV-positive men who have sex with men. AIDS 19: 1407-1414.

Pantanowitz $L$ and Michelow P (2011). Review of human immunodeficiency virus (HIV) and squamous lesions of the uterine cervix. Diagn. Cytopathol. 39: 65-72.

Pimenta AV, Cândido EB, Lima RA, Porto Filho RM, et al. (2011). Importância da infecção anal pelo HPV em mulheres (Importance of anal HPV infection in women). FEMINA 2011: 111-116.

Poggio JL (2011). Premalignant lesions of the anal canal and squamous cell carcinoma of the anal canal. Clin. Colon Rectal Surg. 24: 177-192.

Quaas J, Reich O, Frey Tirri B and Küppers V (2013). Explanation and Use of the Colposcopy Terminology of the IFCPC (International Federation for Cervical Pathology and Colposcopy) Rio 2011. Geburtshilfe Frauenheilkd. 73: 904-907.

Quaas J, Reich O and Küppers V (2014). Explanation and Use of the Rio 2011 Colposcopy Nomenclature of the IFCPC (International Federation for Cervical Pathology and Colposcopy): Comments on the general colposcopic assessment of the uterine cervix: adequate/inadequate; squamocolumnar junction; transformation zone. Geburtshilfe Frauenheilkd. 74: 1090-1092.

Silling S, Kreuter A, Hellmich M, Swoboda J, et al. (2012). Human papillomavirus oncogene mRNA testing for the detection of anal dysplasia in HIV-positive men who have sex with men. J. Clin. Virol. 53: 325-331.

Stanley MA, Winder DM, Sterling JC and Goon PK (2012). HPV infection, anal intra-epithelial neoplasia (AIN) and anal cancer: current issues. BMC Cancer 12: 398.

Stier EA, Sebring MC, Mendez AE, Ba FS, et al. (2015). Prevalence of anal human papillomavirus infection and anal HPVrelated disorders in women: a systematic review. Am. J. Obstet. Gynecol. pii: S0002-9378(15)00264-1. doi: 10.1016/j. ajog.2015.03.034. [Epub ahead of print].

Szarewski A, Ambroisine L, Cadman L, Austin J, et al. (2008). Comparison of predictors for high-grade cervical intraepithelial neoplasia in women with abnormal smears. Cancer Epidemiol. Biomarkers Prev. 17: 3033-3042.

Tornesello ML, Duraturo ML, Giorgi-Rossi P, Sansone M, et al. (2008). Human papillomavirus (HPV) genotypes and HPV16 variants in human immunodeficiency virus-positive Italian women. J. Gen. Virol. 89: 1380-1389.

Valari O, Koliopoulos G, Karakitsos P, Valasoulis G, et al. (2011). Human papillomavirus DNA and mRNA positive result of the anal canal in women with lower genital tract HPV lesions: predictors and clinical implications. Gynecol. Oncol. 122: 505-508.

Wentzensen N, Follansbee S, Borgonovo S, Tokugawa D, et al. (2012). Human papillomavirus genotyping, human papillomavirus mRNA expression, and p16/Ki-67 cytology to detect anal cancer precursors in HIV-infected MSM. AIDS 26: 2185-2192.

Wentzensen N, Follansbee S, Borgonovo S, Tokugawa D, et al. (2014). Analytic and clinical performance of cobas HPV testing in anal specimens from HIV-positive men who have sex with men. J. Clin. Microbiol. 52: 2892-2897. 